\title{
IL-35 expression in hepatocellular carcinoma cells is associated with tumor progression
}

\author{
Jun Long ${ }^{1}$, Hongyan Guo ${ }^{2}$, Shichang Cui ${ }^{3}$, Haiyan Zhang ${ }^{4}$, Xinmin Liu ${ }^{1}$, Danning \\ $\mathrm{Li}^{1}$, Zimeng Han ${ }^{1}$, Linfeng $\mathrm{Xi}^{1}$, Wenyi Kou ${ }^{1}$, Jiangnan $\mathrm{Xu}^{1}{ }^{1}$, Tao-Sheng $\mathrm{Li}^{5}$, Yaozhong \\ Ding ${ }^{1}$ \\ ${ }^{1}$ Department of Immunology, School of Basic Medical Sciences, Capital Medical University, Beijing, 100069, P.R. China \\ ${ }^{2}$ Clinical Laboratory of Beijing Youan Hospital, Capital Medical University, Beijing, 100069, P.R. China \\ ${ }^{3}$ Oncology and Hepatobiliary Minimally Invasive Interventional Center, Beijing Youan Hospital, Capital Medical University, \\ Beijing, 100069, P.R. China \\ ${ }^{4}$ Department of Cell Biology, Municipal Laboratory for Liver Protection and Regulation of Regeneration, Capital Medical \\ University, Beijing, 100069, P.R. China \\ ${ }^{5}$ Department of Stem Cell Biology, Atomic Bomb Disease Institute, Nagasaki University, Nagasaki, 852-8523, Japan \\ Correspondence to: Jun Long, email: longjunj@ccmu.edu.cn \\ Jiangnan Xu, email: xujn@ccmu.edu.cn \\ Tao-Sheng Li, email: litaoshe@nagasaki-u.ac.jp \\ Yaozhong Ding, email: dingyz@ccmu.edu.cn
}

Keywords: IL-35, hepatocellular carcinoma, tumor progression, migration, invasion

Received: March 01, 2016 Accepted: June 03, $2016 \quad$ Published: June 17, 2016

\section{ABSTRACT}

IL-35 has recently been demonstrated to play significant roles in the progression of various malignant tumors. We investigated the expression of IL-35 in hepatocellular carcinoma (HCC) and the regulatory mechanisms in HCC progression. Tissue microarray from 75 HCC patients revealed that IL-35 was primarily localized in the cytoplasm of cancer cells and peri-tumoral hepatocytes. Quantitative analysis showed that IL-35 expression was significantly lower in patients in the advanced stages than in the early stages. Significantly lower expression of IL-35 was also observed in HCC patients with higher histological grades, larger tumor size, positive microvascular invasion and lymph node/distant metastasis. IL-35 over-expression in HepG2 cells significantly upregulated HLA-ABC and CD95, reduced activities of MMP-2 and MMP-9, and decreased cell migration, invasion and colony formation capacities. Our data indicated that decreased expression of IL-35 in tumor tissues might contribute to the progression of HCC, and IL-35 may serve as a new therapeutic target for HCC.

\section{INTRODUCTION}

Interleukin 35 (IL-35) is a heterodimeric cytokine of the IL-12 family [1], mainly expressed in immune cells including the regulatory $\mathrm{T}$ cells $\left(\mathrm{T}_{\text {regs }}\right)[2-4]$, regulatory B cells $\left(B_{\text {regs }}\right)$ [5-6], and plasma cells [7]. As an antiinflammatory and immune inhibitory cytokine, IL-35 has been demonstrated to suppress $\mathrm{T}$ cell proliferation [1], convert naive T cells into IL-35-producing iTr35 [8], and play important roles in inflammatory diseases [9-10], infectious diseases [5, 11-12], autoimmune diseases [13-16], and allograft rejection [17-18].

Interestingly, the positive expression of IL-35 has recently been observed in various malignant tumors [19-24], such as lung cancer [19], pancreatic cancer [20], colorectal cancer [21], nasopharyngeal carcinoma [22] and gastric cancer [24]. It has also been demonstrated that the expression of IL-35 in cancer cells is involved in tumor development and prognosis, presumably due to its immune inhibitory activities. However, the precise role of IL-35 expression in cancer cells remains to be revealed, and we have limited information about the IL-35 expression in hepatocellular carcinoma (HCC), one of the most common types of cancer worldwide [25-26].

In this study, we examined the expression of IL- 35 in different AJCC TNM stages of HCC using a tissue microarray and further analyzed whether IL-35 expression levels were associated with the clinicopathological features of HCC patients. To further confirm the role of IL-35 expression in the progression of $\mathrm{HCC}$, we 
used HepG2 cells (a cell line of HCC) with IL-35 overexpression to investigate how IL-35 over-expression could change the biological characteristics of cells.

\section{RESULTS}

\section{Patients and clinicopathological features}

All tissue samples were collected from patients (63 men and 12 women) who underwent precise hepatectomy with a pathologically confirmed diagnosis of primary HCC, and none of the patients had received radiotherapy or chemotherapy before surgery. The clinical and pathological features of these patients are summarized in Table 1. The median age at diagnosis was 53 years old (range 34 to 73 years old). According to the American Joint Committee on Cancer (AJCC, Seventh Edition) guidelines, patients were determined to be stage I in $17(23 \%)$ cases, stage II in $26(35 \%)$ cases, stage III in 22 cases $(29 \%)$, and stage IV in $10(13 \%)$ cases. Based on the WHO criteria, the histological grade of tumors was defined as grade I in $3(4 \%)$ cases, grade II in $46(61 \%)$ cases, grade III in $25(33 \%)$ cases, and grade IV in $1(2 \%)$ cases.

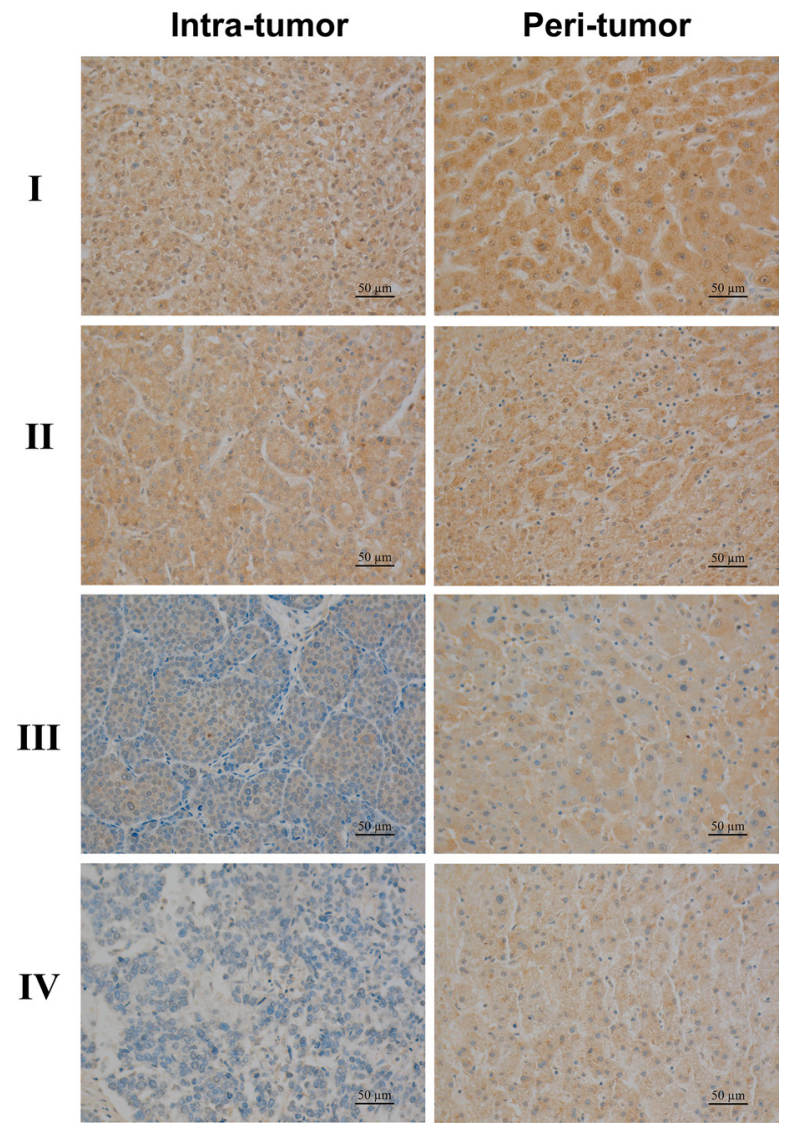

Figure 1: Tissue microarray analysis of IL-35 expression in hepatocellular carcinoma tissues. A anti-human IL-35 mAb was used to stain human hepatocellular carcinoma (HCC) tissues and peri-tumoral liver tissues. Representative images of IL-35 expression in tumor and peri-tumoral liver tissues from HCC patients of AJCC TNM stage I (A, B), II (C, D), III (E, F), IV (G, H). Positive staining was observed mainly in the cytoplasm and partially in the nucleus of cancer cells and peri-tumoral hepatocytes, but stroma cells were negatively stained (bar, $50 \mu \mathrm{m}, 400 \times$ magnification).

\section{Low IL-35 expression levels in HCC tissues associated with poor prognosis of patients}

A tissue microarray containing matched pairs of different stages of primary HCC tissue and adjacent liver tissues from 75 patients was used for immunohistochemical analysis. The expression of IL- 35 was observed in tumoral cells and some hepatocytes around the peri-tumoral zone, and positive staining was mainly localized in the cytoplasm and also weakly observed in the nucleus. However, stroma cells were negative for IL-35 staining (Figure 1A-1H).

We performed semi-quantification of the IL-35 expression by measuring the density of positive staining. Interestingly, the expression levels of IL-35 were significantly higher in the peri-tumoral zone than the intra-tumoral zone $(0.130 \pm 0.010$ vs. $0.093 \pm 0.010$, $p=0.000$ ), and the same situation occurred in the early stages (including AJCC TNM stage I-II, $0.159 \pm 0.012$ vs. $0.120 \pm 0.013, p=0.003$ ) and advanced stages (including AJCC TNM stage III-IV $(0.091 \pm 0.014$ vs. $0.056 \pm 0.012$, $p=0.000)$ (Figure 2).

To further understand how IL-35 expression contributes to the progression of $\mathrm{HCC}$, we investigated

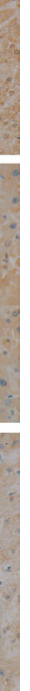


Table 1: clinicopathological features of patients with hepatocellular carcinoma

\begin{tabular}{|c|c|}
\hline Clinicopathological variables & No. of patients (\%) \\
\hline \multicolumn{2}{|c|}{ Age at diagnosis (34-73 yrs, media: 53 yrs) } \\
\hline$\leq 53$ & $43(57)$ \\
\hline$>53$ & $32(43)$ \\
\hline \multicolumn{2}{|l|}{ Gender } \\
\hline Male & $63(84)$ \\
\hline Female & $12(16)$ \\
\hline \multicolumn{2}{|l|}{ Tumor size } \\
\hline$\leq 5 \mathrm{~cm}$ & $28(42)$ \\
\hline$>5 \mathrm{~cm}$ & $38(58)$ \\
\hline \multicolumn{2}{|l|}{ Microvascular invasion } \\
\hline Yes & $24(32)$ \\
\hline No & $51(68)$ \\
\hline \multicolumn{2}{|l|}{ Lymph node metastasis } \\
\hline positive & $5(7)$ \\
\hline negative & $70(93)$ \\
\hline \multicolumn{2}{|l|}{ Distant metastasis } \\
\hline positive & $5(7)$ \\
\hline negative & $70(93)$ \\
\hline \multicolumn{2}{|l|}{ Histological grade of tumor } \\
\hline grade I-II & $49(65)$ \\
\hline grade III-IV & $26(35)$ \\
\hline \multicolumn{2}{|l|}{ AJCC TNM stage } \\
\hline stage I-II & $43(57)$ \\
\hline stage III-IV & $32(43)$ \\
\hline
\end{tabular}

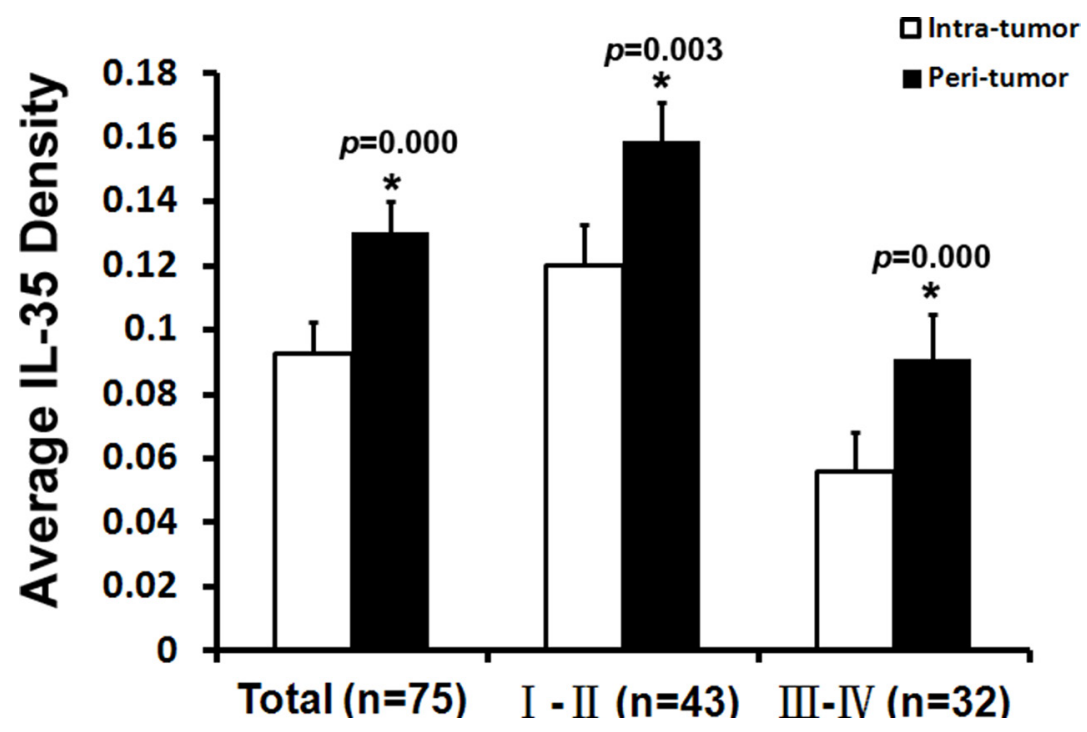

Figure 2: Average density of IL-35 staining in tumor tissue and peri-tumoral liver tissues. Semi-quantification of the IL-35 expression was performed by measuring the density of positive staining. IL-35 densities were significantly higher in the peri-tumoral liver tissue than the intra-tumoral zone, and the same situation occurred for the early stage (AJCC TNM stage I-II) and advanced stage (AJCC TNM stage III-IV). Data are expressed as the mean \pm SEM. (*) The paired samples $t$-test showed a significant difference between the two groups. 
the relationship between IL-35 expression and the clinicopathological features of $\mathrm{HCC}$ patients. Neither age $(p=0.793$, Figure $3 \mathrm{~A})$ nor gender $(p=0.873$, Figure $3 \mathrm{~B})$ was associated with IL-35 expression in HCC patients. However, IL-35 expression was significantly lower in patients with AJCC TNM stages III-IV compared to stages I-II $(0.056 \pm 0.012$ vs. $0.120 \pm 0.013, p=0.000$, Figure 3C). Similarly, significantly lower expression of IL-35 was observed in HCC patients with higher histological grades $(0.059 \pm 0.013$ vs. $0.110 \pm 0.012, p=0.005$, Figure $3 \mathrm{D})$, larger tumor size $(0.065 \pm 0.011$ vs. $0.116 \pm 0.017$, $p=0.018$, Figure $3 \mathrm{E}$ ), positively microvascular invasion $(0.052 \pm 0.014$ vs. $0.112 \pm 0.011, p=0.002$, Figure $3 \mathrm{~F})$ and lymph node/distant metastasis $(0.046 \pm 0.014$ vs. 0.100 $\pm 0.011, p=0.006$, Figure $3 \mathrm{G})$. This result suggests that the decreased expression of IL-35 in tumor tissues might contribute to the progression of HCC.

\section{Over-expression of IL-35 in HepG2 cells significantly upregulated HLA-ABC and CD95, reduced the activities of MMP-2 and MMP-9, and decreased the abilities of cell migration, invasion, and colony formation}

Using established HepG2 cells stably transfected with IL-35-Fc or Fc expression vector [27] (Figure 4A-4B), we sought evidence that IL-35 expression in $\mathrm{HCC}$ cells was directly associated with the progression of HCC. We observed that the over-expression of IL-35 in HepG2 cells significantly decreased cell migration $(26.73 \pm 5.76$ vs. $85.17 \pm 11.17, p=0.027$, Figure 4C-4D) and invasion potency (42.94 \pm 9.25 vs. $72.18 \pm 2.65$, $p=0.030$, Figure 4E-4F). MMP-2 and MMP-9, two of the main proteolytic enzymes for degrading the extracellular matrix (ECM) and the basement membrane, are known to be critical for tumor metastasis. Gelatin zymography assay showed that IL-35 over-expression in HepG2 cells significantly reduced the activities of MMP-2 $(p=0.016)$ and MMP-9 $(p=0.002)$ ( Figure 4G-4H). Furthermore, a colony formation assay showed that HepG2 cells with IL-35 over-expression grew significantly fewer colonies of smaller size compared to HepG2 cells without IL-35 overexpression $(86.33 \pm 2.52$ vs. $119.33 \pm 11.37, p=0.008$, Figure 4I-4J). To further elucidate the underlying mechanism, we examined whether IL-35 over-expression changed the expression levels of HLA-ABC and CD95 in HepG2 cells. We found that IL-35 over-expression also upregulated the expression of HLA-ABC and CD95 ( $p<0.05$ vs. controls) (Figure 5). These results supported that the decreased expression of IL-35 in tumor tissues might contribute to the progression of $\mathrm{HCC}$, likely through anti-tumor immune mechanisms.

\section{DISCUSSION}

In this study, we tried to understand the role of IL-35 on the progression of HCC, one of the most frequent cancers with high lethality worldwide. We found

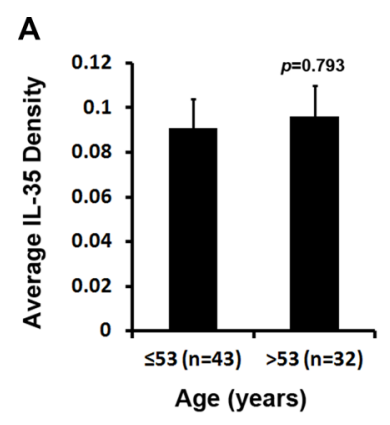

$\mathbf{E}$

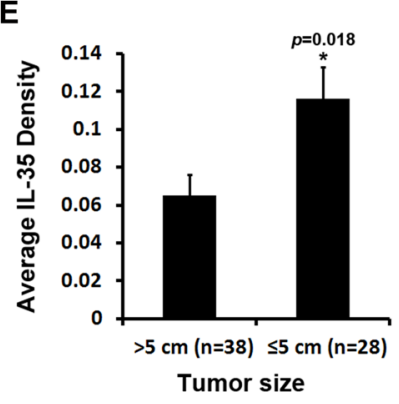

B

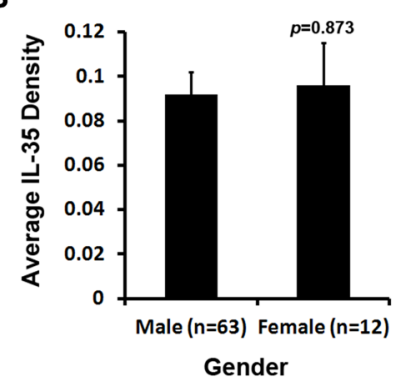

C

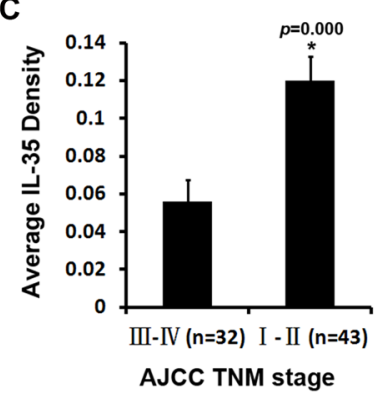

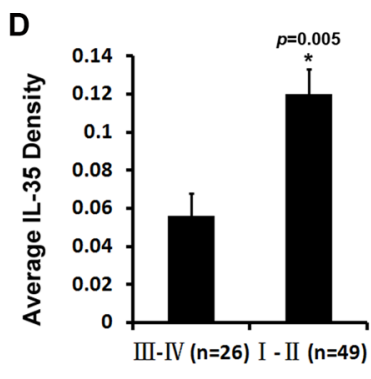

Histological grade of tumor
$\mathbf{F}$

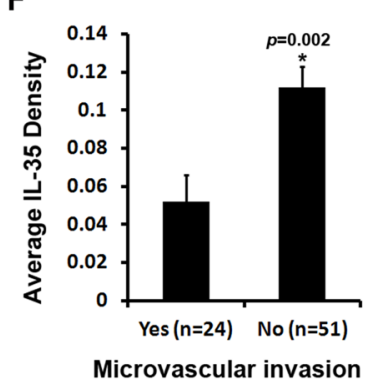

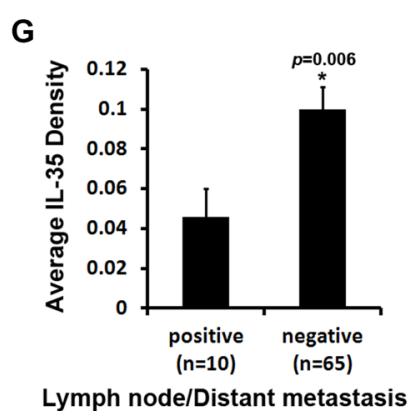

Figure 3: Relationship between IL-35 expression and clinicopathological features of HCC. Semi-quantification of the IL-35 expression was performed by measuring the density of positive staining. Neither age (A) nor gender (B) of patients was significantly associated with IL-35 expression in tumor tissues. However, IL-35 expression was significantly lower in patients with advanced AJCC TNM stages (III-IV) compared to early stages (I-II) (C). Similarly, significantly poorer expression of IL-35 was observed in HCC patients with higher histological grades (D), larger tumor size (E), positive microvascular invasion (F) and lymph node/distant metastasis $(\mathbf{G})$. Data are expressed as the mean \pm SEM. A significant difference between the two groups is indicated by an asterisk (*, Student's $t$-test). 
A

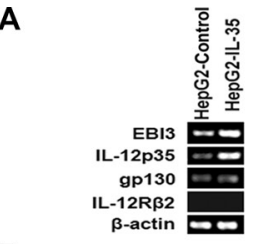

B

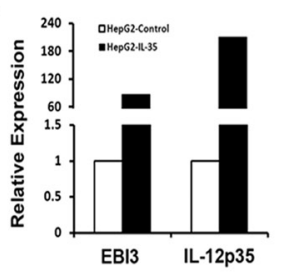

G

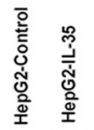

H

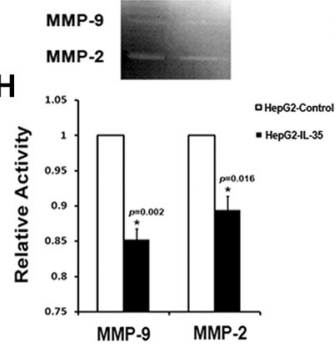

C

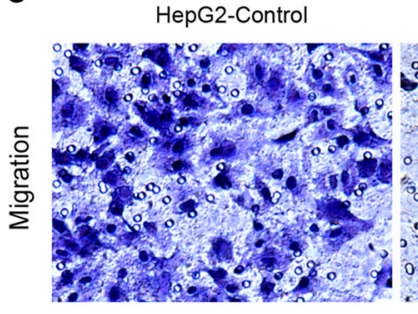

E

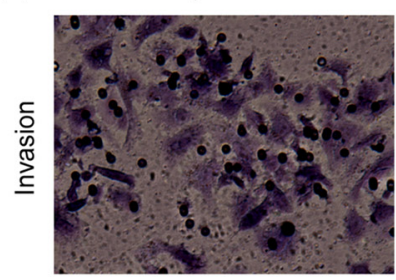

I

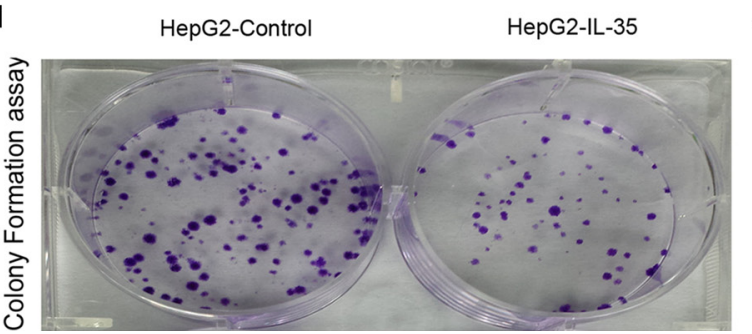

HepG2-IL-35

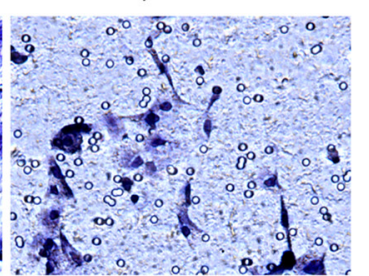

HepG2-IL-35

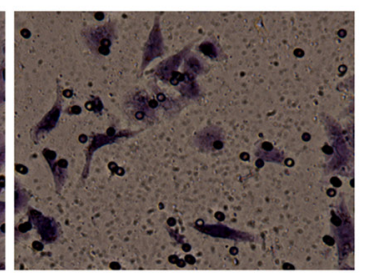

F

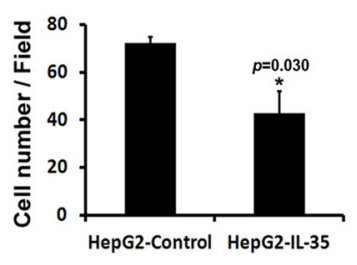

J

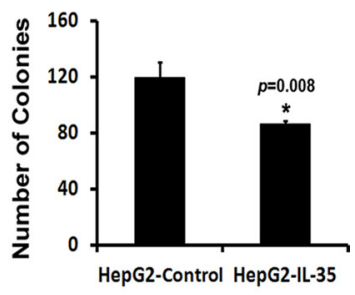

Figure 4: Over-expressing IL-35 in HepG2 cells reduced the activities of MMP-2 and MMP-9, inhibited cell migration, invasion and colony formation in vitro. Detection of IL-35 or IL-35R expression was performed in established HepG2 cells stably transfected with IL-35-Fc or Fc expression vector by RT-PCR (A) and quantitative real-time PCR (B). Cell migration and invasion abilities were determined by a transwell chamber assay. Gelatin zymography assay was conducted to detect active MMP-2 and MMP-9 secretion in cells. The capacity of colony formation was determined by a colony formation assay. The cells that migrated or invaded were stained with $1 \%$ crystal violet solution and visualized by microscopy. Representative images for cell migration $(\times 400, C)$, invasion $(\times 400$, E), gelatin (G) and colony formation (I) in the cells with or without IL-35 over-expression. Quantitative data ( D, F, H, J) represent the mean \pm SD of three independent experiments performed in triplicate. A significant difference between cells is indicated by an asterisk (*, Student's $t$-test). HepG2-Control: HepG2 cells stably transfected with the Fc expression vector. HepG2-IL-35: HepG2 cells stably transfected with the IL-35-Fc expression vector.
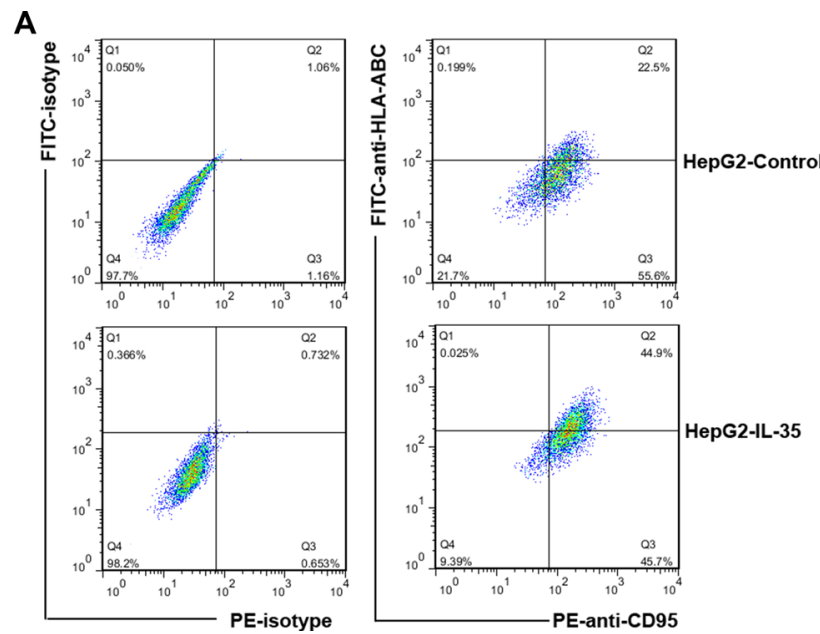

B

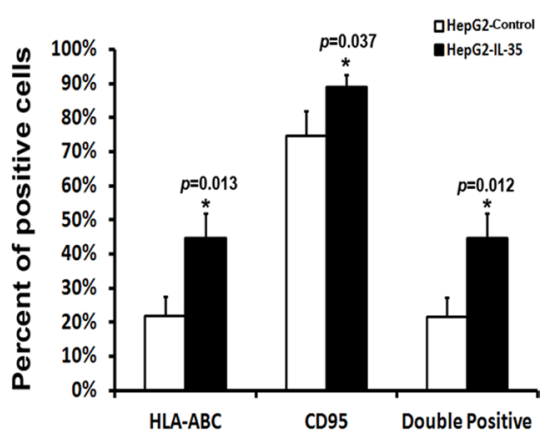

Figure 5: Flow cytometry analysis of the expression of HLA-ABC and CD95 in HepG2 cells. (A) Representative dotgrams showing the expression of HLA-ABC and CD95 in HepG2 cells over-expressing IL-35 and control cells. (B) The percentages of HLA-ABC ${ }^{+}$ cells, $\mathrm{CD} 95^{+}$cells and $\mathrm{HLA}-\mathrm{ABC}+\mathrm{CD} 95^{+} \mathrm{HepG} 2$ cells with IL-35 over-expression and control cells. Columns represent the mean $\pm \mathrm{SD}$ of three independent experiments performed in triplicate. A significant difference between cells is indicated by an asterisk (*, Student's $t$ test). HepG2-Control: HepG2 cells stably transfected with the Fc expression vector. HepG2-IL-35: HepG2 cells stably transfected with the IL-35-Fc expression vector. 
that the expression levels of IL-35 were significantly higher in the peri-tumoral liver tissues than in the tumor tissues. Furthermore, lower IL-35 expression in tumor tissue was observed in HCC patients with AJCC TNM stages, worse histological grades, larger tumor sizes, and histological identification with microvascular invasion and lymph node/distant metastasis. These data indicated that decreased IL-35 might be negatively associated with the prognosis of HCC. In contrast, previous studies showed that the expression of IL-35 increased with advancing tumor stages in colorectal cancer [21] and nasopharyngeal carcinoma [22].

Tumor metastasis and growth is a complicated process involving multiple steps [28], and cell migration, invasion and resistance to cell apoptosis are essential features of the metastatic process [29-30]. Our previous study [27] has revealed that the over-expression of IL- 35 to HepG2 cells enhances apoptotic sensitivity, but little is known about the role of IL-35 expression in the metastasis of HCC. In the present study, we confirmed that the over-expression of IL-35 in HepG2 cells reduced the activities of MMP-2 and MMP-9, significantly decreased cell migration, invasion and single cell colony formation abilities, suggesting a poor potency for metastasis.

The molecular mechanism on IL-35 regulating the progression of HCC remains unclear. IL-35 is well defined as an anti-inflammatory and immune inhibitory cytokine. The tumor can produce a series of mechanisms to evade attack from the immune system, such as the down-regulation of MHC class I and CD95 molecules on the surface of tumor cells. The over-expression of IL-35 in HepG2 cells significantly upregulated HLA-ABC and CD95, suggesting an anti-tumor activity of IL-35 expression in HCC. Recently, Wang et al [23] has reported that IL-35 over-expression in plasmacytoma and melanoma cells does not alter the expression of MHC class I and shows very limited effects on cell growth in vitro, but stimulates tumorigenesis in both immunocompetent and Rag1/2deficient mice through the suppression of tumor immunity. Vignali and colleagues show that Treg cell-derived IL-35 promotes tumorigenesis by contributing to $\mathrm{T}$ cell exhaustion and thereby limiting anti-tumor immunity [31].

The reason for the divergent results between our study and previous reports remains unclear. IL-35 signals through IL-12R $\beta 2$ : gp130 heterodimer or homodimers of each chain, activating transcription factors Stat1 and Stat4 [32]. HepG2 cells express one of IL-35R subunit gp130, but not another subunit IL-12R $\beta 2$ [27]. Therefore, the effects of IL-35 may different greatly depending on the expression, distribution and utilization of receptor complex in different cell types.

In summary, our data provided evidence that IL- 35 was involved in the progression of HCC, probably by directly inhibiting cell activities and indirectly modulating the immune system. IL-35 may serve as a novel prognostic biomarker and therapeutic targets for HCC.

\section{MATERIALS AND METHODS}

\section{Patients and HCC tissue samples}

This study was performed on surgical samples from 75 Chinese patients who underwent precise hepatectomy with pathological confirmation of primary HCC. All samples were obtained following informed consent according to an established protocol approved by the Ethic Committee of Capital Medical University. Clinical information, such as age, gender, presentation and pathological findings including tumor size, microvascular invasion, lymph node status, distant metastasis, histological grade of tumor, and tumor stage, were obtained from the original pathology reports. The data do not contain any information that might lead to the identification of the patients.

\section{Tissue microarray (TMA) and immunohistological staining}

A pair of samples (1.5 $\mathrm{mm}$ in diameter) taken from the primary tumor tissue and peri-tumoral liver tissue (approximately $15 \mathrm{~mm}$ distance from tumor) of each HCC patient was used for the construction of a TMA (in collaboration with Shanghai Xinchao Biotechnology Company, Shanghai, China) as previously described [33]. The constructed TMA was cut into $4 \mu \mathrm{m}$ thick sections for immunohistological staining. Briefly, TMA slides were deparaffinized, rehydrated through graded alcohol, and washed with PBS. Antigen retrieval was performed by microwave-heating sections in $10 \mathrm{mM}$ sodium citrate buffer ( $\mathrm{pH} \mathrm{6)}$ for 10 minutes. After quenching of endogenous peroxidase activity and blocking of nonspecific binding, mouse anti-human IL-35 monoclonal antibodies (Imgenex, San Diego, CA) were added at a specified dilution $(10 \mu \mathrm{g} / \mathrm{ml})$, after which slides were incubated at $4^{\circ} \mathrm{C}$ overnight. HRP conjugated anti-mouse IgG was used as a secondary antibody to detect anti-human IL-35 antibody binding. Chromogenic immunolocalization was performed by exposure to 3, 3'-diaminobenzidine (DAB) substrate. Slides were counterstained with hematoxylin before dehydration and mounting.

The density of positive staining was measured using a computerized image system composed of a Leica CCD camera DFC420 connected to a Leica DM 6000B microscope (Leica Microsystems Imaging Solutions Ltd, Cambridge, United Kingdom). Under high-power magnification $(\times 400)$, photographs of four representative fields were captured by the Leica QWin Plus v3 software. Identical settings were used for each photograph. The IL-35 density was measured by the Image-J software (Media Cybernetics Inc, Bethesda, MD, USA). The integrated optical density of the positive staining of IL-35 in each photograph was measured, and its ratio to total area of each photograph was calculated as the IL-35 staining density. 


\section{Cell culture}

HepG2 cells with established stable IL-35 overexpression and control cells were obtained as previously described [27]. These cells were cultured in high glucose DMEM medium (Hyclone, USA) supplemented with 10\% fetal bovine serum (FBS, Hyclone, USA), 100 units of penicillin/ml (Hyclone, USA), and 100 ng of streptomycin/ $\mathrm{ml}$ (Hyclone, USA). The cells were incubated at $37^{\circ} \mathrm{C}$ in an atmosphere of $5 \% \mathrm{CO} 2$.

\section{RT-PCR and quantitative real-time PCR}

Total RNA was isolated using TRIzol Reagent (Invitrogen, USA), then reverse transcribed into cDNA using the RNA-to-cDNA Kit (Genestar, China). The primer sequences used in this study are shown in Table 2. The PCR products were amplified using the following thermal cycles parameters: $95^{\circ} \mathrm{C}$ for $30 \mathrm{~s}, 60^{\circ} \mathrm{C}$ for $30 \mathrm{~s}$ and $72^{\circ} \mathrm{C}$ for $30 \mathrm{~s}$. The PCR amplicons were visualized using a $2 \%$ agarose gel containing ethidium bromide. The relative gene expression levels were determined using quantitative real-time PCR and the SYBR Green labeling method in a Rotor-Gene Q continuous fluorescence detector (Qiagen, Germany), and the relative gene expression levels were calculated using the $\Delta \mathrm{Ct}$ method, which was normalized to the endogenous $\beta$-actin as a control. The data are expressed as $\mathrm{n}$-fold relative to the control.

\section{Transwell chamber assay}

A transwell chamber assay was used to evaluate the capacity of cell migration and invasion using twochamber plates with a pore size of $8 \mu \mathrm{m}$ according to the manufacturer's instructions (Corning, USA). DMEM with $10 \%$ fetal bovine serum was added to the lower chamber as a chemoattractant. For the invasion assay, $3 \times 10^{4}$ cells were seeded in serum-free medium in the upper chamber coated with extracellular matrigel (ECM) on the transwell filter inserts, while the cell migration assay performed using a coat without ECM (Corning, USA). After incubation at $37^{\circ} \mathrm{C}$ for $48 \mathrm{~h}$, the cells in the upper chamber and on the matrigel were mechanically removed with a cotton swab, and the cells on the outer surface of the membrane were stained with $1 \%$ crystal violet (Sigma, USA). The migrating and invading cells were examined, counted, and photographed by digital microscopy (Leica Microsystems Imaging Solutions Ltd., Cambridge, United Kingdom). Five fields of view per filter were counted; the fields were randomly chosen from the top, bottom, left, right, and center positions of each filter.

\section{Gelatin zymography assay}

A gelatin zymography assay was conducted to evaluate the influence of IL-35 on the activities of matrix metalloproteinase (MMP-2 and MMP-9). $8 \times 10^{5}$ cells were seeded into six-well plates, cultured with serum free medium for $24 \mathrm{~h}$. At the end of incubation, $30 \mu \mathrm{L}$ of culture supernatant was mixed with sample buffer and resolved on a $10 \%$ SDS-PAGE under non-reducing conditions. The gel was co-polymerized containing $1 \mathrm{mg} / \mathrm{mL}$ of gelatin (Sigma, St. Louis, USA). Gel was washed twice for $30 \mathrm{~min}$ with renaturation buffer $(2.5 \%$ Triton X-100) at room temperature before incubation in the incubation buffer $(50 \mathrm{mM}$ Tris- $\mathrm{HCl} \mathrm{pH} 7.5$, $200 \mathrm{mM} \mathrm{NaCl}, 10 \mathrm{mM} \mathrm{CaCl} 2,1 \mu \mathrm{M} \mathrm{ZnCl} 2)$ at $37^{\circ} \mathrm{C}$ for $24 \mathrm{~h}$. Thereafter, gel was stained for $2 \mathrm{~h}$ in $0.5 \%$ coomassie brilliant blue R-250 and then de-stained. White bands were observed against a blue background after de-staining, indicating gelatinolytic activity of MMP-2 and MMP-9. The activities of the MMP-2 and MMP-9 bands were quantified using densitometry by the Image-J software (Media Cybernetics Inc, Bethesda, MD, USA).

\section{Colony formation assay}

HepG2 cells over-expressing IL-35 and control cells were collected, and 300 cells were seeded into six-well plates for 2 weeks. Colonies were fixed with $4 \%(\mathrm{v} / \mathrm{v})$ paraformaldehyde for $20 \mathrm{~min}$ and stained with $1 \%$ crystal violet (Sigma, USA) for $30 \mathrm{~min}$. The number of colonies was measured.

\section{Flow cytometry}

Cells were stained with FITC-labeled antibody against human HLA-ABC and PE-labeled antibody against human CD95(Miltenly). The appropriate isotype controls were used as negative controls. Analytical flowcytometry was performed with a BD FACSAria flow cytometer (BD Biosciences, USA) and the data were analyzed using the FlowJo software (TreeStar, Ashland, OR).

\section{Statistical analysis}

Data are expressed as mean \pm SEM or mean \pm SD. Quantitative variables were analyzed by Student's $t$-test. All statistics were two-tailed, with a $p$ value $<0.05$ considered statistically significant. Analyses were performed using the SPSS software package (version 11.5) (SPSS Inc, Chicago, IL). 
Table 2: The Primer sequences of the target genes

\begin{tabular}{|c|c|c|c|}
\hline Gene & Forward sequence $\left(5^{\prime}-3^{\prime}\right)$ & Reverse sequence $\left(5^{\prime}-3^{\prime}\right)$ & Product size (bp) \\
\hline$E B I 3$ & GCTTCGTGCCTTTCATAACAG & GCTCCCACTGCACCTGTA & 102 \\
\hline$I L-12 p 35$ & ACATGCTGGCAGTTATTGATGA & TGAAGAAGTATGCAGAGCTTGAT & 127 \\
\hline gp130 & GCAGTTTGTGTGCTAAAG & AATGTTGCAAGTGAGCTG & 180 \\
\hline$I L-12 R b 2$ & CAAGAGAGGCGATGTGAC & TGAGAATTGAGGGAGTGG & 180 \\
\hline$\beta$-actin & GCATCCTCACCCTGAAGTAC & TGATCTGGGTCATCTTCTCG & 180 \\
\hline
\end{tabular}

\section{ACKNOWLEDGMENTS AND FUNDINGS}

This work was funded by the Beijing Municipal Natural Science Foundation grants 7142018 and KZ201310025019, and the National Natural Science Foundation of China grant 81370188 .

\section{CONFLICTS OF INTEREST}

We state that no conflicts of interests exist in our study.

\section{REFERENCES}

1. Collison LW, Workman CJ, Kuo TT, Boyd K, Wang Y, Vignali KM, Cross R, Sehy D, Blumberg RS, Vignali DA. The inhibitory cytokine IL-35 contributes to regulatory T-cell function. Nature. 2007; 450:566-569.

2. Chaturvedi V, Collison LW, Guy CS, Workman CJ, Vignali DA. Cutting edge: Human regulatory T cells require IL-35 to mediate suppression and infectious tolerance. J Immunol. 2011; 186:6661-6666.

3. Seyerl M, Kirchberger S, Majdic O, Seipelt J, Jindra C, Schrauf C, Stockl J. Human rhinoviruses induce IL-35producing Treg via induction of B7-H1 (CD274) and sialoadhesin (CD169) on DC. Eur J Immunol. 2010; 40:321-329.

4. Liu F, Tong F, He Y, Liu H. Detectable expression of IL-35 in $\mathrm{CD} 4+\mathrm{T}$ cells from peripheral blood of chronic hepatitis B patients. Clin Immunol. 2011; 139:1-5.

5. Shen P, Roch T, Lampropoulou V, O'Connor RA, Stervbo U, Hilgenberg E, Ries S, Dang VD, Jaimes Y, Daridon C, Li R, Jouneau L, Boudinot P, et al. IL-35-producing B cells are critical regulators of immunity during autoimmune and infectious diseases. Nature. 2014; 507:366-370.

6. Wang RX, Yu CR, Dambuza IM, Mahdi RM, Dolinska MB, Sergeev YV, Wingfield PT, Kim SH, Egwuagu CE. Interleukin-35 induces regulatory $\mathrm{B}$ cells that suppress autoimmune disease. Nat Med. 2014; 20:633-641.

7. Woodle ES, Rothstein DM. Clinical implications of basic science discoveries: janus resurrected--two faces of B cell and plasma cell biology. Am J Transplant. 2015; 15:39-43.

8. Collison LW, Chaturvedi V, Henderson AL, Giacomin PR, Guy C, Bankoti J, Finkelstein D, Forbes K, Workman CJ,
Brown SA, Rehg JE, Jones ML, Ni HT, et al. IL-35mediated induction of a potent regulatory $\mathrm{T}$ cell population. Nat Immunol. 2010; 11:1093-1101.

9. Huang CH, Loo EX, Kuo IC, Soh GH, Goh DL, Lee BW, Chua KY. Airway inflammation and IgE production induced by dust mite allergen-specific memory/effector Th2 cell line can be effectively attenuated by IL-35. J Immunol. 2011; 187:462-471.

10. Whitehead GS, Wilson RH, Nakano K, Burch LH, Nakano H, Cook DN. IL-35 production by inducible costimulator (ICOS)-positive regulatory $\mathrm{T}$ cells reverses established IL-17-dependent allergic airways disease. J Allergy Clin Immunol. 2012; 129:207-215 e201-205.

11. Xiang XG, Xie Q. IL-35: A potential therapeutic target for controlling hepatitis B virus infection. J Dig Dis. 2015; $16: 1-6$.

12. Chen Y, Wang CJ, Lin SH, Zhang M, Li SY, Xu F. Interleukin-35 is upregulated in response to influenza virus infection and secondary bacterial pneumonia. Cytokine. 2016; 81:23-27.

13. Thiolat A, Denys A, Petit M, Biton J, Lemeiter D, Herve R, Lutomski D, Boissier MC, Bessis N. Interleukin-35 gene therapy exacerbates experimental rheumatoid arthritis in mice. Cytokine. 2014; 69:87-93.

14. Tomcik M, Zerr P, Palumbo-Zerr K, Storkanova H, Hulejova H, Spiritovic M, Kodet O, Stork J, Becvar R, Vencovsky J, Pavelka K, Filkova M, Distler JH, et al. Interleukin-35 is upregulated in systemic sclerosis and its serum levels are associated with early disease. Rheumatology (Oxford). 2015.

15. Singh K, Kadesjo E, Lindroos J, Hjort M, Lundberg M, Espes D, Carlsson PO, Sandler S, Thorvaldson L. Interleukin-35 administration counteracts established murine type 1 diabetes - possible involvement of regulatory T cells. Sci Rep. 2015; 5:12633.

16. Niedbala W, Wei XQ, Cai B, Hueber AJ, Leung BP, McInnes IB, Liew FY. IL-35 is a novel cytokine with therapeutic effects against collagen-induced arthritis through the expansion of regulatory $\mathrm{T}$ cells and suppression of Th17 cells. Eur J Immunol. 2007; 37:3021-3029.

17. Liu Y, Wu Y, Wang Y, Cai Y, Hu B, Bao G, Fang H, Zhao L, Ma S, Cheng Q, Song Y, Zhu Z, Chang H, et al. IL-35 mitigates murine acute graft-versus-host disease with retention of graft-versus-leukemia effects. Leukemia. 2014. 
18. Zhang X, Zhou Y, Xu L, Han W, Chen H, Chen Y, Fu H, Zhou S, Zhao J, Wang Q, Feng F, Zhu X, Liu K, et al. Reduced IL-35 levels are associated with increased platelet aggregation and activation in patients with acute graftversus-host disease after allogeneic hematopoietic stem cell transplantation. Ann Hematol. 2014.

19. Nishino R, Takano A, Oshita H, Ishikawa N, Akiyama H, Ito $\mathrm{H}$, Nakayama $\mathrm{H}$, Miyagi $\mathrm{Y}$, Tsuchiya E, Kohno N, Nakamura Y, Daigo Y. Identification of Epstein-Barr virusinduced gene 3 as a novel serum and tissue biomarker and a therapeutic target for lung cancer. Clin Cancer Res. 2011; 17:6272-6286.

20. Nicholl MB, Ledgewood CL, Chen X, Bai Q, Qin C, Cook KM, Herrick EJ, Diaz-Arias A, Moore BJ, Fang Y. IL-35 promotes pancreas cancer growth through enhancement of proliferation and inhibition of apoptosis: evidence for a role as an autocrine growth factor. Cytokine. 2014; 70:126-133.

21. Zeng JC, Zhang Z, Li TY, Liang YF, Wang HM, Bao JJ, Zhang JA, Wang WD, Xiang WY, Kong B, Wang ZY, $\mathrm{Wu} \mathrm{BH}$, Chen XD, et al. Assessing the role of IL-35 in colorectal cancer progression and prognosis. Int J Clin Exp Pathol. 2013; 6:1806-1816.

22. Zhang Y, Sun H, Wu H, Tan Q, Xiang K. Interleukin 35 is an independent prognostic factor and a therapeutic target for nasopharyngeal carcinoma. Contemp Oncol (Pozn). 2015; 19:120-124.

23. Wang Z, Liu JQ, Liu Z, Shen R, Zhang G, Xu J, Basu S, Feng Y, Bai XF. Tumor-derived IL-35 promotes tumor growth by enhancing myeloid cell accumulation and angiogenesis. J Immunol. 2013; 190:2415-2423.

24. Fan YG, Zhai JM, Wang W, Feng B, Yao GL, An YH, Zeng C. IL-35 over-expression is associated with genesis of gastric cancer. Asian Pac J Cancer Prev. 2015; 16:2845-2849.
25. Mittal S, El-Serag HB. Epidemiology of hepatocellular carcinoma: consider the population. J Clin Gastroenterol. 2013; 47:S2-6.

26. Kirstein MM, Vogel A. The pathogenesis of hepatocellular carcinoma. Dig Dis. 2014; 32:545-553.

27. Long J, Zhang X, Wen M, Kong Q, Lv Z, An Y, Wei XQ. IL-35 over-expression increases apoptosis sensitivity and suppresses cell growth in human cancer cells. Biochem Biophys Res Commun. 2013; 430:364-369.

28. Chambers AF, Groom AC, MacDonald IC. Dissemination and growth of cancer cells in metastatic sites. Nat Rev Cancer. 2002; 2:563-572.

29. Pienta KJ, Loberg R. The "emigration, migration, and immigration" of prostate cancer. Clin Prostate Cancer. 2005; $4: 24-30$.

30. Townson JL, Naumov GN, Chambers AF. The role of apoptosis in tumor progression and metastasis. Curr Mol Med. 2003; 3:631-642.

31. Turnis ME, Sawant DV, Szymczak-Workman AL, Andrews LP, Delgoffe GM, Yano H, Beres AJ, Vogel P, Workman CJ, Vignali DA. Interleukin-35 Limits AntiTumor Immunity. Immunity. 2016; 44:316-329.

32. Collison LW, Delgoffe GM, Guy CS, Vignali KM, Chaturvedi V, Fairweather D, Satoskar AR, Garcia KC, Hunter CA, Drake CG, Murray PJ, Vignali DA. The composition and signaling of the IL-35 receptor are unconventional. Nat Immunol. 2012; 13:290-299.

33. Qian YB, Zhang JB, Wu WZ, Fang HB, Jia WD, Zhuang PY, Zhang BH, Pan Q, Xu Y, Wang L, Tang ZY, Sun HC. P48 is a predictive marker for outcome of postoperative interferon-alpha treatment in patients with hepatitis B virus infection-related hepatocellular carcinoma. Cancer. 2006; 107:1562-1569. 